\title{
The effect of luminance on metacontrast with internally contoured targets
}

\author{
DONNA ARAND and WILLIAM N. DEMBER \\ University of Cincinnati, Cincinnati, Ohio 4522I
}

\begin{abstract}
Recent studies have provided evidence which contradicts the previous finding that target detectability decreases with increases in the number of internal contours in the target. The present study attempted to reconcile these discrepant findings by examining the effect of luminance level on detectability of internally contoured targets under mask and no-mask conditions. The results showed that the different luminance levels used in these studies may have indeed contributed to the discrepant results.
\end{abstract}

Visual perception does not occur instantaneously. When an image of the world strikes the retina of the eye, it activates a series of intricate processes which take time to transform the retinal image into a percept. Normally, an image is completely processed in the time it takes to shift our gaze and fixate another object. However, in the laboratory it is possible to present two stimuli in such rapid succession that the second stimulus occurs before the first stimulus is completely processed. As a result, the second stimulus (the mask) may decrease the detectability of the first stimulus (the target). This inhibitory effect is generally referred to as backward masking; the term "metacontrast" is used when the first and second stimuli do not spatially overlap.

Since its discovery in 1910 by Stigler, backward masking has provided a means for "stopping" the visual image at various points during processing in order to delineate the various stages of processing as well as to study the variables which affect those stages. In particular, many vision researchers have used metacontrast as a device to help reveal the operation of visual inhibitory processes.

Of particular interest to the present study is the work of Dember and his co-workers, who have been engaged in a series of experiments stemming from Werner's pioneering work dealing with the effect of configurational variables on metacontrast. In his classic experiment, Werner (1935) employed a target disk followed by a surrounding black ring and reported that target disks containing internal contours were harder to mask than a homogeneous black disk.

Werner's findings relied on the phenomenal reports of his subjects; a study was undertaken by Sherrick and Dember (1970) to replicate Werner's results using an objective psychophysical task. As expected, the results demonstrated that a half-black half-white target disk was harder to mask than a homogeneous black disk. In an

Requests for reprints should be sent to William N. Dember, Department of Psychology, University of Cincinnati, Cincinnati, Ohio 45221. attempt to determine whether resistance to masking was quantitatively related to the number of internal target contours, a number of studies compared the detectability of targets having $2,4,8,16$, and 32 alternating black and white spoked segments (Cox \& Dember, 1970; Dember, Mathews, \& Stefl, 1973; Dember \& Stefl, 1972; Ellis \& Dember, 1971). The results from these studies consistently demonstrated that in a no-mask condition increases in the number of target segments produced a decrease in target detectability, whereas in a masking condition increases in the number of target segments resulted in a decrease in target maskability. In fact, the Dember and Stefl study (1972) confirmed earlier demonstrations that the mask served to enhance rather than decrease the detectability of the 16-segmented target. Subsequently, Dember, Mathews, and Stefl (1973) found enhancement for 24-, 28-, and 32-segmented targets as well.

Though the present studies have obtained consistent findings, a very recent study by Lefton (1974) has reported the opposite effect. Employing the disk-ring paradigm, Lefton used a solid target as well as targets containing 6,12 , and 18 alternating black and white spoked segments. Lefton found that in the masking condition target detectability decreased as the number of segments increased. Furthermore, Lefton found no evidence of an enhancement effect.

In an effort to identify possible variables which may have contributed to these discrepant results, we have noted several methodological differences between the studies of Lefton and those of Dember and his collaborators. A major difference lies in the luminance levels employed in the two groups of studies. Lefton has used a luminance level of $.41 \mathrm{fL}$, whereas Dember has typically employed much higher levels, specifically 10 , 20 , and $25 \mathrm{fL}$. Such a difference in luminance levels may possibly account for the discrepant results since several studies have shown that luminance levels affect the degree of masking obtained (e.g., Cox \& Dember, 1971; Purcell, Stewart, \& Dember, 1969).

The purpose of the present study was to investigate 
the effect of different luminance levels on the maskability of internally contoured targets in the disk-ring paradigm. It was expected that Lefton-type results would be obtained at low luminance levels and that the outcomes reported in the Dember studies would occur at the higher luminance levels.

\section{METHOD}

\section{Subjects}

Three male and three female paid college students with normal or corrected-to-normal vision served as subjects. Each subject was trained on the experimental task for $1 \mathrm{~h}$ on each of 2 days prior to the collection of the data.

\section{Stimuli}

The three targets consisted of a homogeneous black disk and two half-black half-white disks having either 8 or 16 alternating black and white pie-shaped segments. The masks consisted of a pair of homogeneous black rings and a blank white card (nomask condition). The horizontally arranged masking rings fit snugly around the target disks. The stimuli are shown in Figure 1.

The diameter of the disks and the inner diameter of the rings subtended $24 \mathrm{~min}$ of arc and the walls of the rings subtended $12 \mathrm{~min}$ of arc. The distance between ring centers subtended 58 min of arc. All stimuli were photographs of black ink drawings which were mounted on white index cards.

\section{Apparatus and Procedure}

The stimuli were presented tachistoscopically (Scientific Prototype Model GX) in the following order: light fixation field, target, mask, light fixation field. The termination of the target marked the onset of the mask. This sequence defined a trial. The time between trials was about $10 \mathrm{sec}$. The duration of the target was varied in order to obtain threshold measures, but the duration of the mask remained constant at $105 \mathrm{msec}$. Five luminance levels were used: $.5,2.5,5,10$, and $20 \mathrm{fL}$. Each subject served in each of the 30 stimulus conditions ( 3 targets by 2 masks by 5 luminance levels). Viewing was monocular.

Each subject received two conditions on each of 15 days of testing. The order of presentation of the stimulus conditions was randomized independently for each subject.

All subjects were adapted to the fixation field for $5 \mathrm{~min}$ before the start of each test session. On each trial, the experi-
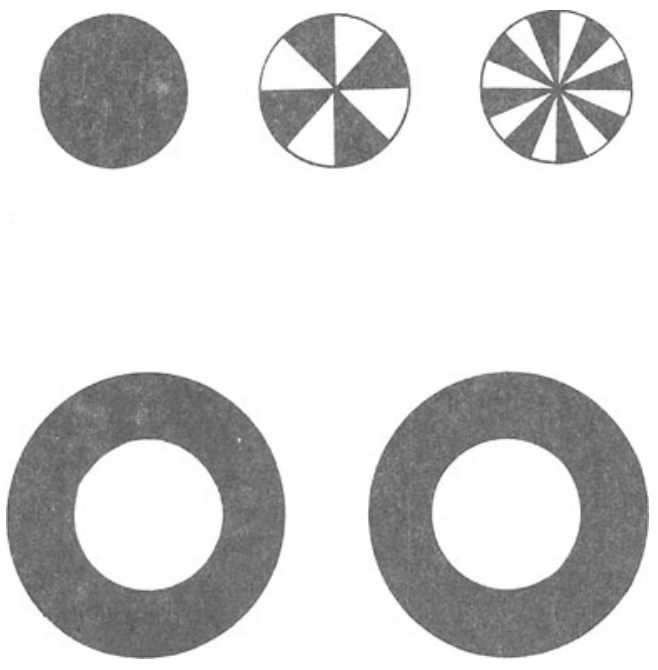

Figure 1. Target and mask stimuli. menter placed the disk so that it fit snugly within one of the two rings, the specific disk location being random. In the no-mask condition, the disk was also randomly placed in one of the two positions it would have occupied if rings were present. On a signal from the experimenter, the subject pushed a button, initiating the sequence. The subject then indicated, by saying "right" or "left," in which of the two positions the target appeared, guessing if necessary.

The detection threshold of a disk in a particular stimulus combination was determined by varying the target duration, using the staircase method (Dixon \& Massey, 1969). A staircase series was conducted by presenting the subject with a target of a given duration. If the subject responded correctly on two successive trials, target duration was decreased $.5 \mathrm{msec}$; if the subject was incorrect, target duration was increased $.5 \mathrm{msec}$ on the next trial. An ascending and descending staircase series were intermixed in order to control for anticipation effects. Whether a given trial came from an ascending or descending series was randomly determined. At the beginning of each stimulus combination, a preliminary series of 15 trials was run to obtain a rough estimate of the threshold for that condition. This estimate was used to determine the beginning points of the ascending and descending staircases.

Thirty-five data points from each staircase were collected. The first five data points in each series were not used in the analysis since these points merely allowed the two staircases to approach one another. The remaining 60 data points (30 from each staircase series) were used in the calculation of the threshold values.

\section{RESULTS AND DISCUSSION}

Duration thresholds for all conditions for each subject were calculated according to the procedure outlined in Dixon and Massey (1969). A three-way repeated measures analysis of variance was performed on the data. There was a significant main effect due to targets $[\mathrm{F}(2,10)=5.17, \mathrm{p}<.05]$, with the 8-segmented target showing the lowest threshold and the solid target showing the highest threshold overall. Mask condition was also significant $[F(1,5)=447.98, p<.001]$, indicating that thresholds were lower in the no-mask condition. There was also a main effect due to luminance $[F(4,20)=29.82, p<.001]$, indicating greater masking at the lower luminance levels. The interaction of Mask Condition by Luminance Level was significant $[F(4,20)=3.20, p<.05]$, revealing greater masking at the lower luminance levels only in the ring mask condition. Finally, there was a significant triple interaction of Target by Mask by Luminance Level $[\mathrm{F}(8,40)=3.56$, $\mathrm{p}<.05$ ], which is illustrated in Figure 2.

The results of the present study did support the hypothesis that luminance is an important factor in masking and may indeed have contributed to the contradictory results of the Dember and Lefton studies. Specifically, the results demonstrated that more masking occurred at the low luminance level used by Lefton than at the higher levels used by Dember. Furthermore, Lefton's failure to find an enhancement effect for the 16-segmented target is consistent with the present data, which show that masking for the 16-segmented target was extraordinarily high at the lowest luminance level, while at the higher luminance levels less masking oc- 


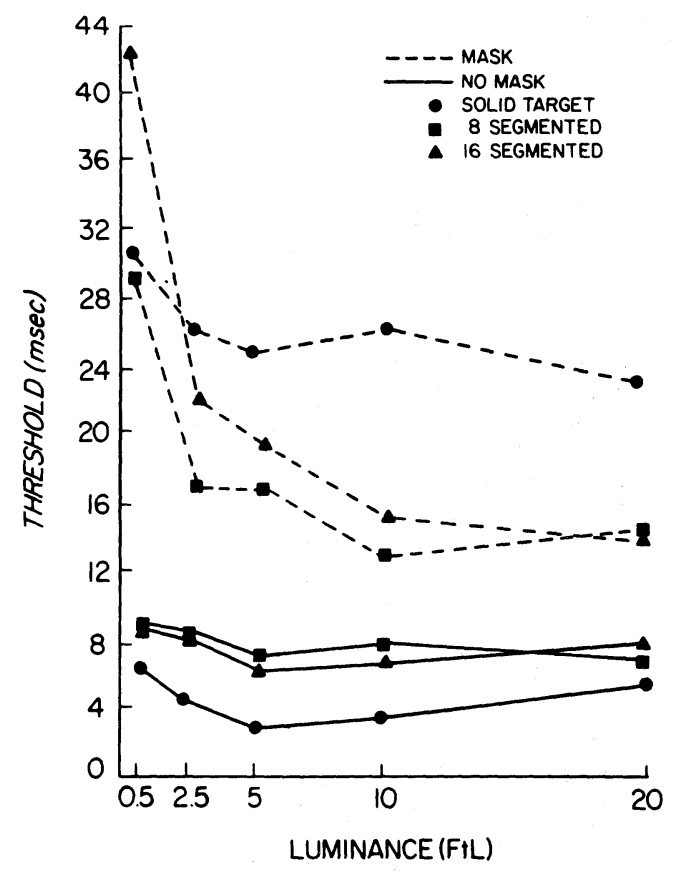

Figure 2. Mean duration thresholds for each mask, target, and luminance condition.

curred. However, though masking was the lowest for the 16-segmented target at the highest luminance level, an absolute enhancement effect was not found in the present study.

From a theoretical standpoint, the present study demonstrates that the inhibitory processes involved in visual perception are extremely sensitive to overall luminance levels. Specifically, the data suggest that, while a stimulus presentation may activate both excitatory and inhibitory components, the luminance level determines the relative strength of each. At low luminance levels the inhibitory component is more dominant, while the reverse is true at high luminance levels. This latter statement is strongly supported by the fact that the same stimulus combination, a 16-segmented target and a solid mask, can produce exactly opposite effects at low and high luminance levels. Also, the fact that the stimuli in the no-mask condition are relatively unaffected by luminance level further suggests that any change in the relative amounts of inhibitory and excitatory components are due to an interaction between target and mask components. It seems that at low luminance levels the excitatory component of the target interacts with the inhibitory component of the mask, whereas at high luminance levels the excitatory component of the target interacts less with the mask's inhibitory component. In the case of enhancement, the excitatory component of the target seems to interact with the excitatory component of the mask.

Recently formulated masking theories of Breitmeyer and Ganz (1976) and Weisstein, Ozog, and Szoc 1975) propose that masking effects are due to the interactions between components of the target and mask. However, these theories seem unable to account for the present data since they deal with luminance or energy variables only in terms of stimulus onset asynchrony (SOA). These theories fail to consider possible effects of luminance when other stimulus parameters, particularly SOA, remain relatively constant. The present data demonstrate the need to incorporate the effect of luminance under various conditions into any model of masking, since luminance may profoundly alter, up to the point of excluding, the various inhibitory processes that occur during metacontrast.

\section{REFERENCES}

Breitmeyer, B. G., \& Ganz, L. Implications of sustained and transient channels for theories of visual pattern masking, saccadic suppression, and information processing. Psychological Review, 1976, 83, 1-36.

Cox, S., \& DEMBER, W. N. Backward masking of visual targets with internal contours. Psychonomic Science, 1970, 19, 225-226.

Cox, S., \& Dember, W. N. Effects of target-field luminance, interstimulus interval and target-mask separation on extent of visual backward masking. Psychonomic Science, 1971, 22, 79-80.

Dember, W. N., Mathews, W. D., \& Stefl, M. Backward masking and enhancement of multi-segmented visual targets. Bulletin of the Psychonomic Society, 1973, 1, 45-47.

Dember, W. N., \& Stefl, M. Backward enhancement? Science, $1972,175,93-95$.

Dixon, J. W., \& MASSEY, F. J. Introduction to statistical analysis. New York: McGraw-Hill, 1969.

Ellis, D., \& DemBer, W. N. Backward masking of visual targets with internal contours: A replication. Psychonomic Science, 1971, 22, 91-92.

LEFTON, L. Internal contours, intercontour distance, and interstimulus interval. Journal of Experimental Psychology, 1974, 103, 891-895.

Purcell, D., Stewart, A., \& Dember, W. N. Facilitation of visual backward masking by increasing target duration: A methodological extension. Psychonomic Science, 1969, 17, 360-361.

SherRick, M. F., \& Dember, W. N. Visual backward masking and the area-detection relation. Psychonomic Science, 1970, 19, 127-128.

STIGLER, R. Chronophotische Studien uber den Umgebungskontrast. Pflügers Archiv für die gesamte Physiologie, 1910, 134, 365-435.

Werner, H. Studies on contour: I. Qualitative analysis. American Journal of Psychology, 1935, 47, 40-64.

Weisstein, N., Ozog, G., \& Szoc, R. A comparison and elaboration of two models of metacontrast. Psychological Review, $1975,82,325-343$.

(Received for publication October 3, 1977.) 